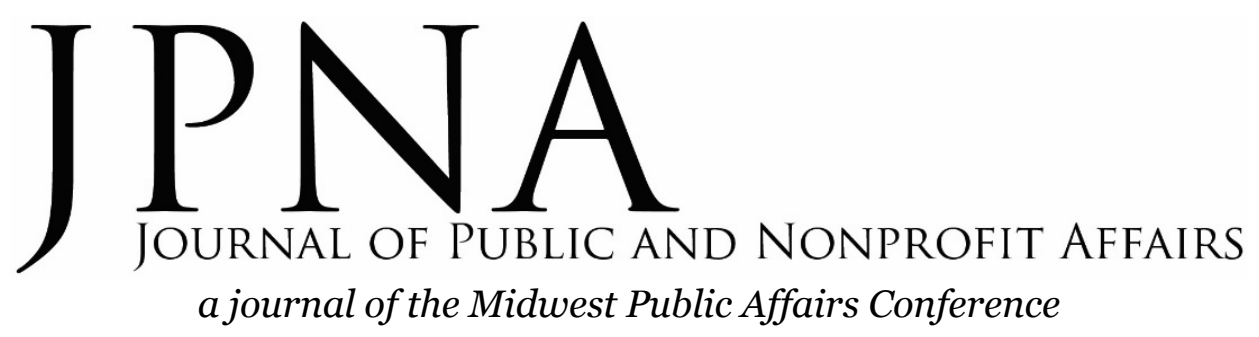

\title{
Spring 2019
}

Volume 5, Number 1

Introduction to the Issue

Lindsey M. McDougle .................................. 3

\section{Research Articles}

The History and Evolution of the Southeastern Conference for Public Administration David Berlan, Ruowen Shen, and $W$. Earle Klay .................... 6

Managing Citizen Satisifaction: Is Good Not Enough?

Brian K. Collins, Hyun Joon Kim, and Jie Tao . . . . . . . . . . . . . . . . 21

Rethinking the Social Welfare Regime Model: The Case of Public Policy Toward Israeli

Philanthropists

Hanna Shaul Bar Nissim and Hillel Schmid . . . . . . . . . . . . . . . 39

Managing Risk and Growth of Nonprofit Revenue

Dwight V. Denison, Wenli Yan, and J. S. Butler ................... 56

Building Capacity in Nonprofir Boards: Learning from Board Self-Assessments Judith L. Millesen and Joanne G. Carman . . . . . . . . . . . . . . . . . 74

\section{Current Issues in Practice}

Managing Volunteer Retirement among Older Adults: Perspectives of Volunteer Administrators

Allison R. Russell, Melissa A. Heinlein Storti, and Femida Handy . . .

\section{Book Review}

Valuing Bureaucracy: The Case for Professional Government by Paul R. Verkuil Tyler Klatt 
